\title{
Trabalhadores acidentados/ adoecidos no Complexo do Alumínio-Barcarena (Pará) e a negação dos direitos sociais
}

\author{
Injured/sickened workers at the Aluminum Complex \\ at Barcarena, Pará and the denial of social rights
}

\author{
Nelceli Silva Melo* \\ Vera Lúcia Batista Gomes**
}

\begin{abstract}
Resumo - O artigo apresenta uma análise sobre a negação dos direitos sociais dos trabalhadores acidentados e adoecidos pelo trabalho no Complexo do Alumínio em Barcarena (Pará), instalado na Amazônia paraense. Tem como base uma pesquisa empírica realizada em 2015, cujos sujeitos foram 11 trabalhadores e 3 representantes de organizações políticas nesse complexo. Os dados foram analisados procurando problematizar os direitos sociais que estão sendo negados a esses trabalhadores e os seus principais determinantes. Evidenciamos, aqui, que as condições de trabalho nas empresas deste complexo fazem uso, ao mesmo tempo, de tecnologias avançadas e obsoletas, com inúmeras combinações químicas tóxicas e prejudiciais à saúde e à vida dos trabalhadores. Desse modo, os trabalhadores são expostos a acidente/adoecimento, culminando na negação dos direitos sociais e na invisibilidade da exploração do trabalho na Amazônia.

Palavras-chave: Amazônia; complexo do alumínio; condições de trabalho; acidente/adoecimento no trabalho; direitos sociais.

Abstract - This article investigates the denial of injured or sickened worker's social rights at the Barcarena, Pará Aluminum Complex, in the Amazon. It is based on empirical research carried out in 2015 with eleven workers and three representatives of political organizations at the Complex. The data was analyzed to investigate the social rights of these workers, which are being denied, and the main causes for this. It was found that the working conditions in the companies that make up this Complex involve technologies both advanced
\end{abstract}

\footnotetext{
*Assistente Social do Centro de Referência de Saúde do Trabalhador - CEREST/Pará. Mestre em Serviço Social pelo PPGSS-UFPA, pesquisadora na área do Trabalho, Saúde do Trabalhador. Membro do Grupo de Estudos e Pesquisas Trabalho, Estado e Sociedade na Amazônia/PPGSS-UFPA. Correspondência: Conjunto Abelardo Conduru, Quadra 09, Casa 13. Bairro Coqueiro. Ananindeua-PA. CEP: 67015-090. Email: <nelcelism@gmail.com>.

** Doutora em Sociologia do Trabalho pela Université de Picardie Jule Verne - Amiens/France. Pós-Doutora em Serviço Social (PPGSS/UFPE) e em Sociologia pelo Instituto de Sociologia/Universidade do Porto - Portugal. Docente na Universidade Federal do Pará - UFPA. Coordenadora do Grupo de Estudos e Pesquisas Trabalho, Estado e Sociedade na Amazônia/PPGSS-UFPA. Correspondência: Trav. Quintino Bocaiúva, 436/505-Reduto. Belém-Pará. CEP: 66053 -240. Email:<veralucia@ufpa.br>.
} 
and obsolete, with numerous toxic chemical combinations harmful to health. This puts the lives of workers at risk, predisposing them to injury or sickness, culminating in the denial of social rights and the invisibility of exploitative labor practices in the Amazon.

Keywords: Amazon; aluminum complex; working conditions; work related injuries/sickness; social rights.

\section{Introdução}

A elaboração deste artigo parte da constatação de que as condições de trabalho nas empresas do Complexo de Alumínio, instalado no município de Barcarena (PA) ${ }^{1}$, expõem os trabalhadores a produtos químicos e a temperaturas elevadas de até $960^{\circ} \mathrm{C}(\mathrm{CASTRO}, 2009)$. Além disso, nas últimas décadas, os trabalhadores vêm sofrendo pressões por parte das gerências para o cumprimento de metas de produtividade, implicando na intensificação da exploração da força de trabalho na Amazônia. Com efeito, tem-se o desgaste físico, mental e social dos trabalhadores, que ficam predispostos a acidentes/adoecimentos causadores da "interrupção forçada de trabalho" (LOURENÇO, 2011, p. 5).

Atualmente, o Complexo do Alumínio em Barcarena (PA) é composto pelas seguintes multinacionais: 1) Hydronorte, de capital norueguês (empresas Albras e Alunorte) e 2) Empresa Alubar, de capital argentino. Cada empresa é responsável por um tipo de atividade que dinamiza o Complexo do Alumínio: Alunorte transforma a bauxita em alumina, sendo $80 \%$ desse produto exportado, ficando apenas $20 \%$ na região ${ }^{2}$. Desses $20 \%$, apenas $10 \%$ são beneficiados em alumínio na Albras e os outros $10 \%$ em produtos como vergalhões e cabos pela Alubar. Essas empresas multinacionais passaram a exigir do Estado nacional um aparato de estrutura local, dando origem aos grandes projetos na Amazônia ${ }^{3}$, controlando política e economicamente os governos.

Nesta direção, o Complexo do Alumínio foi uma estratégia utilizada, por certas nações centrais, para o enfrentamento da crise do capitalismo, instaurada nos anos 1970, através da busca por "outros países para instalar parte de suas plantas industriais" (SANTIAGO, 2007, p. 50). Assim, houve uma nova partilha do mundo, ou melhor, o processo de neo-

\footnotetext{
1 O município de Barcarena possui uma distância, em linha reta, de 30km de Belém. Além disso, possui o IDH-M-0,662 (médio) (PNUD, 2013).

${ }^{2}$ Ver: <www:http://grces.com.br>: Acesso em: 10 jul. 2015.

${ }^{3}$ Para Leal (1988), a concepção de Grande Projeto é usada, quase que exclusivamente, para referir-se ao enclave mineiro na região Amazônica, ou seja, a grande quantidade de infraestrutura (transportes, energia, tecnologia e formação de força de trabalho qualificada) criada para tornar viável a extração de minérios, visando ao pagamento da dívida externa acumulada pelos governos anteriores.
} 
colonização dos últimos espaços históricos existentes para a expansão do capital. Portanto, o referido complexo é tributário da dinâmica do capitalismo na Amazônia que, para Marques e Trindade (2014), fora planejado nos anos 1950, sendo levado a ferro e fogo nas décadas de 1960 e 1970, durante a Ditadura Militar. Por conta disso, especialmente na Amazônia paraense, foram implantados diversos grandes projetos, dentre os quais podem ser destacados: Trombetas, em 1960, com a exploração da bauxita; Grande Carajás, em 1970, com a exploração de minério de ferro e o complexo mina-ferrovia-porto; Hidrelétrica de Tucuruí, em 1970; AlbrasAlunorte, em 1976, com a produção de alumina e alumínio metálico, dentre outros (NASCIMENTO, 2009).

A esse propósito, registra-se que: "Nas últimas décadas, do século XXI, a expansão econômica na Amazônia é crescentemente vinculada aos mercados globais, especialmente à produção de soja, carne, madeira e minérios" (RIVERO; COONEY, 2012, p. 206), dada a tendência da reprimarização ${ }^{4}$ da América Latina. As considerações levaram ao questionamento a respeito dos direitos sociais dos trabalhadores, os quais estão sendo negados, bem como seus principais determinantes.

$\mathrm{Na}$ tentativa de responder a essas questões, foi realizada uma pesquisa empírica, cujos dados obtidos estimularam a construção deste artigo. Esta pesquisa teve seu projeto submetido ao Comitê de Ética em Pesquisa da Universidade Federal do Pará (UFPA), sendo iniciada após aprovação e homologação deste comitê por meio do Parecer Consubstanciado $\mathrm{n}^{\mathrm{o}}$ 1.233.601 (BRASIL, 2015).

Para investigar os direitos sociais negados aos trabalhadores vitimados por acidente/adoecimento no trabalho no Complexo do Alumínio em Barcarena (PA), que é o objetivo deste trabalho, optou-se pela abordagem do tipo qualitativa, haja vista que esta possibilita o "[...] contato direto com os sujeitos da pesquisa" (MARTINELLI, 1999, p. 22) e, dessa forma, permitiu-nos conhecer as opiniões deles a respeito da situação. Como instrumentos de coletas de dados, fez-se uso da entrevista semiestruturada, da observação e análise documental nas fichas do Serviço de Acolhimento e nos relatórios de monitoramento do Centro de Referência Estadual em Saúde do Trabalhador do Pará (Cerest-PA).

Assim, a pesquisa qualitativa possibilitou ouvir 11 trabalhadores e 3 representantes das entidades políticas do ramo do alumínio no município de Barcarena (PA) acerca da negação dos direitos sociais. As entrevistas ocorreram nas residências e nas sedes das entidades representativas dos trabalhadores, sendo ambas localizadas nos municípios de Belém, Barcarena e Abaetetuba, no estado do Pará. No que concerne à coleta de dados, cada

\footnotetext{
${ }^{4}$ Moreira e Magalhães (2014) utilizam o termo reprimarização para referir-se a um novo padrão exportador de especialização produtiva para a América Latina, que associa elementos ditos estruturais destas economias ao ciclo do capital na economia dependente, baseado em produtos essencialmente primários. Seria o elemento central da expansão capitalista.
} 


\section{meVistg am paltg}

\} TRABALHADORES ACIDENTADOS/ADOECIDOS - MELO, N. S.; GOMES, V. L. B. \}

DOI: $10.12957 /$ REP.2016.27843

sujeito da pesquisa foi consultado quanto ao interesse em participar, tendo por base o Termo de Consentimento Livre e Esclarecido (TCLE) e, com isso, assumiu-se o compromisso de não identificá-los; por conseguinte, os nomes apresentados e referidos pelos pesquisados são fictícios. No que se refere aos representantes dos trabalhadores, preferiu-se por não identificar os cargos dos entrevistados, apenas as entidades, já que são públicas.

Em linhas gerais, a primeira etapa da pesquisa foi composta pela organização dos dados, conforme "[...] foram construídos e recolhidos" (WOLCOTT apud GOMES et al., 2005, p. 186). A segunda etapa constituiuse na elaboração de estruturas de análise, sendo que o estudo partiu das seguintes categorizações: trabalhadores doentes com direitos sociais negados e com vínculo de trabalho; trabalhadores doentes com direitos sociais parcialmente atendidos e com vínculo de trabalho; e trabalhadores acidentados/ adoecidos com direitos sociais negados e demitidos. A partir dessas categorizações, buscou-se classificar o conjunto dos depoimentos ou registro de observações "[...] dos grupos ou por tipo de instrumento de coleta de dados" (GOMES et al, 2005, p. 190), na perspectiva de identificar e analisar quais são os direitos sociais que estão sendo negados aos referidos trabalhadores, bem como os seus principais determinantes.

O artigo encontra-se estruturado da seguinte maneira: introdução, abordando o tema do texto; breve análise sobre as condições de trabalho no Complexo de Alumínio-Barcarena (PA) e sua relação com a situação de acidente/adoecimento dos trabalhadores; considerações sobre os direitos sociais, objetivando contribuir para a identificação dos direitos que estão sendo negados aos mencionados trabalhadores; os resultados obtidos com a elaboração deste artigo, procurando analisar a negação dos direitos dos trabalhadores pesquisados; e, por último, as considerações finais, com destaque para os principais determinantes da negação dos direitos sociais.

\section{As condições de trabalho no Complexo do Alumínio e os acidentes/adoecimentos dos trabalhadores}

Como proposta de desenvolvimento para a Amazônia, teve-se a implantação do Complexo do Alumínio no município de Barcarena (PA), que provocou o surgimento de um leque de novas relações sociais e mudanças ambientais e econômicas, "[...] transformando, com isso, a realidade e a paisagem, até então, existentes" (MONTEIRO; MONTEIRO, 2009, p. 20). Em consequência, o estado do Pará apresentou, conforme dados do Anuário Brasileiro de Proteção (2014), no período de 2008 a 2010, os maiores índices de acidentes de trabalho e óbitos registrados na indústria de transformação ${ }^{5}$, seguidos do setor de construção, comércio e veículos.

\footnotetext{
${ }^{5}$ Segundo o Anuário Brasileiro de Proteção (2014), a metalurgia faz parte da indústria de transformação, pois transforma minérios ferrosos e não ferrosos em produtos metalúrgicos (alumina e lingotes).
} 


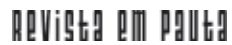

\} TRABALHADORES ACIDENTADOS/ADOECIDOS - MELO, N. S.; GOMES, V. L. B. \}

DOI: $10.12957 /$ REP.2016.27843

Segundo a Associação Brasileira do Alumínio (ABAL, 2015), nessa cadeia produtiva, em 2010, a taxa média de frequência de acidentes com afastamento (relação do número de acidentes por um milhão de horas-homem trabalhadas) foi de 2,76 contra a de 7,39 registrada no ano 2000, ou seja, houve uma importante redução de $63 \%$ no período e queda de $18 \%$ com relação a 2009, dados esses que chamam atenção ao apresentarem uma regressão intensa de $66 \%$ ao longo da última década. Contudo, essa taxa pode ser maior, pois as condições de trabalho na mineração são insalubres, portanto, prejudiciais à saúde dos trabalhadores. Além disso, a subnotificação de acidentes de trabalho tem sido recorrente no Brasil.

Segundo Pará (2014), dos 340 trabalhadores acolhidos no Serviço de Acolhimento do Cerest-PA, no período de 2008 a 2014, 8,91\% (28 pessoas) pertenciam ao projeto Albras/Alunorte. No que se refere ao local de moradia destes, todos residiam em municípios do estado do Pará, tais como: $50 \%$ (14), a maioria, em Barcarena; 28,58\% (8) em Belém; 10,52\% (3) em Abaetetuba; e 10,52 (3) em Ananindeua. Dentre esses trabalhadores, 71,42\%, (20) tinham cargos de operadores, com tipificações diferentes, e 14,28\% ocupavam outros cargos da área fim das atividades das empresas. Logo, $85,71 \%$ (24), ou seja, a maioria exercia atividades na área fim, e apenas $14,29 \%$ (4) na área meio (administrativa) das empresas. Assim, os agravos à saúde dos trabalhadores que mais se destacaram foram: acidente de trabalho típico em $60,71 \%$, seguido de 17,85\% com Lesão por Esforço Físico Repetitivo/Doenças Osteomusculares Relacionadas ao Trabalho (LER/Dort).

Ao se relacionar os agravos à saúde com a ocupação dos trabaIhadores, percebeu-se que os mesmos exerciam atividades operacionais, trabalhando diretamente nos fornos e máquinas do chão de fábrica das empresas do mencionado ccomplexo. Desta forma, cabe registrar que não existe, ainda, uma estatística oficial a respeito do quantitativo dos acidentados e adoecidos pelo trabalho nas empresas. Por isso, a Associação em Defesa dos Reclamantes e Vitimados por Doença do Trabalho na Cadeia Produtiva do Alumínio e Afins no Estado do Pará (ADRVDT-PA, 2015) ${ }^{6}$ realizou um estudo, em 2015, no qual pôde constatar que os sintomas e o início do processo de adoecimento relacionado às doenças osteomusculares ocorrem, com frequência, nos quatro primeiros anos de trabalho.Sobre os agravos à saúde dos trabalhadores, Castro (2009) coloca que as doenças e mutilações precoces são decorrentes das características das condições de trabalho das referidas empresas, que são "[...] extremante agressivos (tanto físico, como emocionalmente), os empregados, na sua maioria, não conseguem se manter em plena capacidade produtiva a partir dos 51 anos" (CASTILHO, 2008, p. 96). Além disso, Castro (2009) enfatiza que a falta de políticas de saúde e segurança das empresas do Complexo do Alumínio em

${ }^{6}$ A ADRVDT tem o propósito de investigar as omissões no encaminhamento de trabalhadores à Previdência Social, os acordos firmados, os longos períodos de benefício etc. 


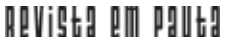

\} TRABALHADORES ACIDENTADOS/ADOECIDOS - MELO, N. S.; GOMES, V. L. B. \}

DOI: $10.12957 /$ REP.2016.27843

Barcarena (PA) contribui para o agravamento dessa situação. Esse quadro remete à necessidade de identificar quais são os direitos negados dos vitimados por acidente/adoecimento no trabalho, tendo em vista a insegurança social vivenciada pelo trabalhador perante a possibilidade de um futuro sombrio, dada a sua nova condição humana de mutilado, provocada pelo trabalho.

\section{Direitos sociais: uma compreensão necessária}

A análise da negação dos direitos sociais dos trabalhadores vítimas de acidentes/adoecimentos pelo trabalho conduz, inicialmente, a efetuar breves considerações sobre direitos sociais, conforme se segue. Segundo Marshall (1967), os direitos sociais surgiram no feudalismo e destinavamse ao âmbito local, sendo que, posteriormente, alargaram-se para o nacional e o mundial, ou seja, davam-se naturalmente.

Sob outro enfoque, no final do século XVIII surgiu um "[...] segundo tipo de direitos" (HOBSBAWM, 2000, p. 423), necessários à nova ordem social emergente; porém, ao mesmo tempo eles se mesclavam e superavam os anteriores. Eram conhecidos como Direitos do Homem, constituindo as bases para as Declarações de Direitos Humanos e, na efervescente Revolução Francesa, para a Declaração dos Direitos do Homem e do Cidadão. Desse modo, esses direitos visavam garantir a liberdade, a propriedade etc., contrapondo-se às ideias absolutistas. No entanto, eram insuficientes, propiciando aos:

[...] movimentos operários, cuja reivindicação básica era por salários decentes pelo trabalho, por previdência social, da qual eles viriam sem dúvidas precisar em algum momento de suas vidas, por benefícios que a pobreza os impedia de usufruir - como cuidado médico e educação escolar - e por direitos políticos não incluídos nas clássicas declarações que tornariam mais fácil sua luta pelos outros direitos, por exemplo, de formar sindicatos e o direito à greve. (HOBSBAWM, 2000, p. 425).

Para Hobsbawm (2000), nenhum outro grupo da sociedade estava tão interessado na reformulação dos direitos do que a classe operária, visto como esta vivia em situação de fome e desemprego, além de ter de enfrentar extensivas jornadas de trabalho. Nesse contexto, a jornada de trabalho foi questionada pela classe trabalhadora, dando visibilidade à luta de classes, a partir de "[...] uma luta multissecular entre o capitalista e o trabalhador" (MARX, 1994, p. 307), por meio "[...] de uma longa e progressiva batalha" (COUTINHO, 2008, p. 42). Desta forma, diferentemente dos direitos civis e políticos, os direitos sociais deram-se através da conquista da redução da jornada de trabalho e foram o resultado de lutas sociais deflagradas no século XVIII e XIX, nos países capitalistas desenvolvidos, tendo em vista que: 
[...] são fundamentados pela ideia de igualdade, uma vez que decorrem do reconhecimento das desigualdades sociais gestadas na sociedade capitalista [...]. [...] expressam-se pelo direito à educação, à saúde, à assistência e à previdência. Os direitos sociais possuem caráter redistributivo, buscam promover a igualdade de acesso a bens socialmente produzidos, a fim de restaurar o equilíbrio para a coesão social. (COUTO, 2010, p. 48).

Sob esta ótica, os direitos sociais permitem "ao cidadão uma participação mínima na riqueza material e espiritual criada pela sociedade" (COUTINHO, 2008, p. 63). Para tanto, segundo Couto (2010), a concretização dos direitos sociais depende da intervenção do Estado, de condições econômicas e de uma base fiscal para efetivá-los e, assim, realizar a justiça social. Desse modo, a materialidade dos direitos sociais depende de um conjunto de mediações possuidoras de uma dupla dimensão: a objetiva e a subjetiva (ideológica), ou seja, de condições "econômicas, institucionais, jurídico-formais, ideoculturais, políticas e partidárias" (COUTINHO, 2008, p. 63). Acrescenta-se a isso a necessidade de correlação de forças em um determinado momento histórico para fazer valer as reivindicações dos indivíduos e/ou da coletividade.

Seguindo esta linha de raciocínio, Pereira (2008) aponta que os direitos civis (direito à propriedade, direito de ir e vir, direito de imprensa etc.) fizeram emergir os tribunais de justiça; já os direitos políticos (direito de votar e ser votado), os parlamentos e conselhos de governos locais; os direitos sociais, as instituições para executarem políticas públicas, entendidas como "as ações do Estado face às demandas e necessidades sociais da sociedade, desde que aquele se tornou crescentemente interventor" (PEREIRA, 2008, p. 87).

Entretanto, para Coutinho (2008), as instituições públicas, junto com a burocracia, representam um obstáculo à universalização dos direitos sociais, pois usam métodos de processos seletivos voltados para os segmentos que interessam à reprodução social do capital. Logo, as políticas públicas são contraditórias, pois, ao mesmo tempo que respondem a determinadas demandas da classe trabalhadora, aceitas pelo Estado burguês, são manipuladas e adaptadas ao interesse da classe dominante. Eis a razão pela qual o processo de regulação social do trabalho, no Brasil, deu-se, paulatinamente, obedecendo à importância do setor produtivo, por exemplo: os trabalhadores do comércio e do banco foram os primeiros a terem aprovado o direito de férias, em 1933, sendo estendido no ano seguinte aos trabaIhadores da indústria etc.

Nesta direção, as primeiras políticas compensatórias foram criadas no Brasil em 1923, a exemplo da Eloy Chaves, que fundou a Caixa de Aposentadoria e Pensão dos Ferroviários. A finalidade era instituir um fundo para empregador, empregado e Estado depositarem contribuições financeiras, cujo objetivo destinava-se a servir ao trabalhador no período de 


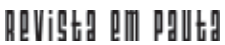

\} TRABALHADORES ACIDENTADOS/ADOECIDOS - MELO, N. S.; GOMES, V. L. B. \}

DOI: $10.12957 /$ REP.2016.27843

desligamento da produção por motivo de velhice e invalidez, ou à sua família, em decorrência de morte, além de assistência médica. Portanto, "[...] tratava-se de um esquema clássico, em que o empregado abre mão de parte de sua renda no presente, enquanto ainda participa do processo de acumulação, a fim de obter parte dela, no futuro, quando dele já estiver ausente" (SANTOS, 1998, p. 78).

Registra-se que, enquanto a sociedade salarial nos países capitalistas desenvolvidos, na década de 1970, entrava em declínio, o Brasil fazia um processo inverso, ao adotar esse modelo de proteção social, mesmo sendo uma sociedade de frágil assalariamento. Desse modo, o não estabelecimento da "sociedade salarial"7 no Brasil colocou limites à lógica de universalização da proteção social, conforme a lógica originária de "garantia do direito social a partir da ocupação de um emprego com carteira de trabalho assinada" (BOSCHETTI, 2006, p. 65).

Para Boschetti (2006, p. 11), o Brasil não viveu uma generalização de salários e empregos estáveis; pelo contrário, tem-se relações sociais de trabalho "[...] extremamente instáveis e restritas a um pequeno número de indivíduos", que passou a sofrer acidentes/adoecimentos no trabalho por conta dos processos produtivos.

Na contramão, segundo Faleiros (2010), a representação sindical anárquica realizou fortes pressões ao Estado no intuito de o mesmo intervir nesta realidade. Ainda de acordo com o autor, foi assim que nasceu a preocupação do Estado brasileiro com a saúde e segurança dos trabalhadores; entretanto, esta só passou a efetivar-se acompanhada das prioridades governamentais para a economia brasileira.

No sentido de elucidar melhor essa questão, Faleiros (2010) relaciona a política de saúde e segurança do trabalho no Brasil ao desenvolvimento da economia brasileira. Para tanto, organiza sua análise em quatro momentos: o primeiro refere-se à expansão das fábricas e máquinas, no início do século XX, durante a hegemonia da oligarquia agroexportadora do café, sendo marcado por intensos conflitos devido às mortes e acidentes que ocorriam no interior das fábricas. Tal situação levou ao aparecimento do movimento sindical. Por conseguinte, em 1904, surgiu a primeira medida de regulamentação dos acidentes de trabalho, só vindo a se efetivar após 15 anos, ou seja, em 1919. Registra-se que esta lei baseou-se no conceito internacional de acidente de trabalho, vinculado à teoria objetiva do risco profissional que o concebe como inerente ao trabalho e ao processo produtivo. Sob esta ótica, o acidente de trabalho decorre de falha humana, denominada de "ato inseguro", ou "uma falha material, conhecida como condição insegura" (VILELA, 2003, p. 43). As consequências dessa abor-

\footnotetext{
${ }^{7}$ A concepção de sociedade salarial é compreendida pelo sociólogo francês Robert Castel como as garantias e direitos do proletariado. À medida que o salário deixa de ser a retribuição pontual de uma tarefa, passando a "assegurar direitos, oferece acesso às subvenções extra trabalho, como doenças, acidentes, aposentadorias e permite uma participação ampliada na vida social (consumo, habitação, e lazer)" (FERREIRA, 2013, n.p.).
} 
dagem recaem, principalmente, na negação da relação do processo produtivo com a ocorrência do acidente de trabalho, além de conceber a indenização ao trabalhador acidentado/adoecido como uma concessão de privilégio social, e não como direito social.

O segundo momento, para Faleiros (2010) ocorreu com a industrialização durante a Era Vargas que, sob a hegemonia burguesa-rural-corporativista, criou mecanismos de controle social da classe trabalhadora pelo Estado. Entretanto, em resposta às reivindicações do movimento sindical, a lei de 1919 sofrera duas modificações: a primeira, em 1934, e a segunda, em 1944, a qual atribuiu ao Estado maior intervenção nos seguros contra acidente de trabalho, assim como representou os primeiros passos para a implantação de uma política de reinserção do trabalhador na produção. Com efeito, o regime de indenização do acidente de trabalho foi mantido, sendo que os seguros privados se tornaram obrigatórios.

Ainda conforme Faleiros (2010), o terceiro momento estendeuse entre o final da II Grande Guerra Mundial e o início da Ditadura Militar, período do surgimento de movimento nacionalista, no Brasil, que desencadeou uma mobilização para a estatização dos seguros de acidentes e a unificação da Previdência Social, em 1960.

Já o quarto momento analisado por Faleiros (2010) refere-se ao período da Ditadura Militar, quando se intensificou a internacionalização da economia através da entrada das multinacionais no Brasil, com estímulos à industrialização de bens duráveis, sendo que a produtividade ficou sem o prolongamento da jornada de trabalho. Registra-se que, nesse período, ocorreram muitos acidentes de trabalho devido ao Milagre Econômico; assim, a Consolidação da Legislação do Trabalho (CLT) de 1943 fora alterada com a promulgação da Portaria n. 3.214/1978, ainda vigente.

Neste momento, segundo Faleiros (2010), a Política de Saúde e Segurança do Trabalho teve a prevenção de acidentes de trabalho como sua maior expressão, com a estatização dos seguros e exigindo que o Estado estivesse no "interior" das fábricas (FALEIROS, 2010, p. 24). Depois desses momentos, presencia-se a elaboração e promulgação da Constituição Federal de 1988, que, segundo Boschetti (2006), foi fruto da conjugação das forças políticas e sociais existentes na sociedade brasileira. Desta forma, a Constituição Federal de 1988, vigente até o presente momento, é considerada pelos brasileiros como a Constituição cidadã e humana, ao preconizar a garantia da proteção social, por meio da Seguridade Social. Nesse sentido, foi somente com a promulgação desta Constituição que os direitos sociais foram instituídos no Brasil, tendo o modelo de Seguridade Social como sistema de proteção social assegurado a todos os brasileiros.

Nesta direção, a referida Constituição traz um título específico que trata da ordem social (Título VII), onde estão elencados os direitos sociais relativos à saúde, Previdência Social, assistência social, educação, entre outros. Dentre tantos direitos sociais previstos nessa Constituição, o 


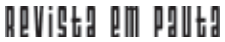

\} TRABALHADORES ACIDENTADOS/ADOECIDOS - MELO, N. S.; GOMES, V. L. B. \}

DOI: $10.12957 /$ REP.2016.27843

direito à saúde faz parte do tripé da Seguridade Social (assistência social, Previdência Social e saúde) e é concebido como um "direito de todos e dever do Estado, garantido mediante políticas sociais e econômicas que visem à redução do risco de doença e de outros agravos, e ao acesso universal e igualitário às ações e serviços para sua promoção, proteção e recuperação" (BRASIL, 1988, p. 116-7).

Com o passar do tempo, os direitos sociais foram paulatinamente sendo regulamentados, em especial o Sistema Único de Saúde (SUS) e a Previdência Social. Desse modo, o SUS foi regulamentado com a promulgação da Lei n. 8.080/90, sendo que antes da sua criação (o SUS completou 26 anos em 2015) a saúde não era considerada um direito social. O modelo de saúde adotado até então dividia os brasileiros em três categorias: os que podiam custear serviços de saúde privados; os que possuíam direito à saúde pública por serem segurados pela Previdência Social (trabalhadores com carteira assinada); e os que não possuíam direito algum. Diante disso, o SUS foi criado para oferecer atendimento igualitário, para cuidar e promover a saúde de toda a população, constituindo-se num projeto social único que se materializa por meio de ações de promoção, prevenção e assistência à saúde dos brasileiros, com destaque para a saúde do trabalhador.Partindo dessa compreensão, segundo Laurell e Noriega (1989), a saúde do trabalhador constituiu-se em um novo modo de entender e analisar o processo saúde-doença, como sendo decorrente também do social, e não somente dos determinantes biológicos. Dessa maneira, afirma-se que a saúde do trabalhador não nega os riscos e os agravos/efeitos para a saúde, mas os considera, também, como decorrentes do processo de trabalho, que é o seu objeto de investigação (LAURELL; NORIEGA, 1989; LACAZ, 1996; MINAYO-GOMEZ; THEDIM apud LACAZ; GÓMEZ, 2005).

Nesta direção, segundo Laurell e Noriega (1989), devido à necessidade de se amenizar os impactos dos conflitos surgidos entre o capital e o trabalho no corpo do trabalhador, o Estado e o patronato adotaram, no século XIX, duas vertentes da medicina, quais sejam: a atenção médica e a dos riscos de trabalho, cuja base científica é o modelo médico ${ }^{8}$ que inspirou a Medicina do Trabalho e a Saúde Ocupacional, as quais contribuíram para a classe dominante manter o controle da força de trabalho no processo produtivo (LAURELL; NORIEGA, 1989).

Assim, historicamente, a concepção de saúde do trabalhador surgiu na Itália, com o Movimento Operário, ao se questionar o modelo médico existente na época. Desenvolveu-se, desse modo, uma nova perspectiva de

\footnotetext{
${ }^{8}$ Explica a doença por agentes específicos - os riscos - e a solução em ações curativas. Esse tipo de método, segundo Laurell e Noriega (1989), obscurece a complexa relação entre processo de trabalho e saúde, na medida em que restringe o entendimento da relação da doença com o trabalho à explicação dos riscos.

${ }^{9}$ Surgiu com a Revolução Industrial e teve como proposta a inserção do profissional médico nas fábricas para desempenhar atividades de preservação da saúde da força de trabalho. Para tanto, este profissional baseia-se na premissa de que é essencial a "descoberta e o controle do agente etiológico causador da doença, no caso identificando no ambiente onde desenvolve o trabalho" (VILELA, 2003, p. 86).
} 
compreensão da relação do processo saúde-doença, tendo a centralidade do processo de trabalho na relação trabalho-saúde:

Assim, por exemplo, na Itália, a Lei 300, de 20 de maio de 1970 ('Norme per la libertá e la dignitá dei lavoratori, della libertá sindicale e dell'attivitá sindicale nei luoghi di lavoro'), mais conhecida como 'Estatuto dos Trabalhadores', incorpora princípios fundamentais da agenda do movimento de trabalhadores, tais como a não delegação da vigilância da saúde ao Estado, a não monetização do risco, a validação do saber dos trabalhadores e a realização de estudos e investigações independentes, o acompanhamento da fiscalização, e o melhoramento das condições e dos ambientes de trabalho. (MENDES; DIAS, 1991, p. 345).

Pelo exposto, essa legislação sustentava-se na concepção de não monetarização do risco, na não aceitação de níveis adversos de trabalho, na não garantia de adicionais salariais, como o de insalubridade, além de incorporar o saber operário nos estudos dos problemas relacionados à saúde dos trabalhadores. Com efeito, as conquistas adquiridas com o Estatuto dos Trabalhadores expandiram-se aos trabalhadores americanos, ingleses, franceses, noruegueses e canadenses, dentre outros. Na América Latina, a nova abordagem do processo saúde-doença no trabalho ganhou espaço e esteve relacionada à crise de paradigma científico na área da Medicina, tendo em vista que esta não conseguia mais explicar o surgimento das novas doenças causadoras de mortalidade na população. Assim, um fator determinante para a mudança de paradigma, segundo Laurell e Noriega (1989), foi o fato de a teoria marxista, nos anos 1970, ter sido a corrente hegemônica nas Ciências Sociais latino-americana ${ }^{10}$.

No que se refere à Previdência Social, foi promulgada a Lei 8.213/ 91 que instituiu os benefícios previdenciários, sendo que o seguro acidentário manteve-se controlado pelo Estado, e sob a responsabilidade do empregador. Dessa maneira, a teoria do risco foi afastada, dando lugar à 'responsabilidade objetiva, ou seja, a responsabilidade do empregador é presumida, por implementação da teoria da socialização do risco, como meio de se dar prevalência ao social' (SALVADOR; PAULO FILHO, 2011, p. 209). Contudo, a política de indenização dos acidentes de trabalho contribuiu para tornar os riscos 'socialmente aceitáveis' (MENDES; WUNCH; OLIVEIRA, 2014, p.128), sendo restritas aos trabalhadores de carteira assinada. Com isso, as políticas sociais, voltadas para a saúde dos trabalhadores, vêm se dando de forma fragmentada e focalizada, o que contribui para culpabilização dos trabalhadores. Na contramão dessa tendência, tem-se a concepção de que: [...] os acidentes de trabalho e doenças profissionais ocorrem em determinadas condições, num contexto de

\footnotetext{
${ }^{10}$ Segundo os autores, a existência de um grupo de trabalho Classe Operária e condições de trabalho no Consejo Latinoamericano de Ciencias Sociales (Clacso), na América Latina e, especialmente, no México, fez as investigações sobre o processo de trabalho e saúde aproximarem as ciências sociais com as ciências da saúde.
} 
relações estabelecidas entre os agentes no processo de produção. São influenciados por fatores relacionados à situação imediata de trabalho, como o maquinário, a tarefa, o meio técnico ou material, e também pela organização do trabalho, em sentido amplo, ou seja, pelas relações de trabalho. (DWYER; LAFLAMME apud VILELA, 2003, p. 39-40).

Diante do exposto, observa-se que esta concepção sobre acidentes de trabalho e doenças profissionais traz em seu bojo a relação do processo produtivo com a ocorrência do acidente de trabalho, tendo como base o paradigma da saúde do trabalhador. Este paradigma, no Brasil, é resultado de todo um processo de luta dos trabalhadores. Assim, trata-se de um "grosseiro equívoco, tanto teórico quanto histórico, falar em democracia burgue$\mathrm{sa}^{\prime \prime}$, pois a história dos direitos evidencia a luta dos trabalhadores para a conquista dos direitos fundamentais. "Portanto, seria não somente um equívoco histórico, mas também uma injustiça contra os trabalhadores atribuir à burguesia algo que foi conquistado contra ela" (COUTINHO, 2008, p. 62).

Ora, se os direitos sociais são conquistas da classe trabalhadora e a concretização desses direitos depende da correlação de forças em determinado momento histórico, cabe interrogar sobre os direitos sociais dos trabalhadores vítimas de acidente/adoecimento pelo trabalho exercido no Complexo do Alumínio (PA) que estão sendo negados. Estas questões ganham sentido, sobretudo, pelo fato de que, a partir dos anos 1990, segundo Antunes (2009), o Brasil adotou o Estado neoliberal, que criou uma nova roupagem para o capitalismo: mais duro e livre da intervenção estatal. Nesse processo de precarização do trabalho, os capitais globais passaram a exigir o desmonte da legislação social que ampara o trabalhador, forçando os governos nacionais a aderirem à acumulação flexível. Sob esta lógica, segundo Soares (2003), os gastos com os direitos sociais passaram a ser considerados generosos e culpados pelos déficits fiscais. Por isso, os estados que ainda os mantêm em suas legislações foram chamados de paternalistas e estimuladores da preguiça. Desta forma, tem-se uma política de ajustes global à economia mundial, com "[...] rearranjo de hierarquia das relações econômicas e políticas internacionais feitos sob a égide de uma doutrina neoliberal, cosmopolita, gestada no centro financeiro e político do mundo capitalista" (SOARES, 2003, p. 12), conduzindo ao retrocesso dos direitos de cidadania conquistados pelos brasileiros com a promulgação da Constituição Federal de 1988.

\section{A negação dos direitos sociais dos trabalhadores acidentados/ adoecidos pelo trabalho no Completo do Alumínio - Barcarena (PA)}

A análise dos principais determinantes da negação dos direitos sociais dos trabalhadores adoecidos/acidentados pelo trabalho no Complexo do Alumínio - Barcarena (PA) conduziu à compreensão do processo de 
reestruturação produtiva, ocorrido na década de 1990, nas empresas ali instaladas. Isto porque o complexo alterou as relações de trabalho, afetando ainda mais a saúde dos trabalhadores. No entanto, as duas maiores empresas realizaram investimentos tecnológicos de forma diferenciada: na Alunorte, conforme o relato do representante do Sindiquímicos deu-se, prioritariamente, no setor administrativo; na Albras, por sua vez, Gomes e Castro (2004) apontaram o setor produtivo, a exemplo da substituição da cuba eletrolítica (fornos a céu aberto) pela semiautomática (fornos fechados), diminuindo, desta forma, temperaturas de até $1.100^{\circ} \mathrm{C}$ para até $960^{\circ} \mathrm{C}$ (CASTRO, 2009). Todavia, esses investimentos tecnológicos não eliminaram: as altas temperaturas e o campo magnético existente nesse tipo de tecnologia (cubas eletrolíticas); as inúmeras combinações químicas tóxicas, como a bauxita, o ferro e o manganês, dentre outros, utilizadas para o beneficiamento dos minerais; e nem, tampouco, o "[...] esforço físico muito grande do ser humano" (de acordo com representante sindical do Sindiquímicos).

Pelo exposto, essas mudanças sinalizam uma modernização conservadora, pois as ideologias da gestão pela qualidade total baseada em metas de produtividade mesclaram-se ao uso de tecnologias obsoletas. A exemplo, tem-se, na área operacional da Alunorte, um maquinário parecido com aqueles existentes no início da Revolução Industrial. Tal analogia pôde ser realizada a partir de análises de imagens fotográficas do local de trabalho de um dos entrevistados; contudo, por conta da política de privacidade da empresa, não será possível mostrá-las aqui.

Evidencia-se, então, que nessas empresas as condições de trabalho dão-se em ambientes insalubres, indicando de imediato o não cumprimento das legislações brasileiras (BRASIL, 1943; 1991; 1999) quanto à diminuição e neutralização de suas características insalubres. Nesta direção, chama a atenção, também, os instrumentos de trabalho que, segundo os representantes sindicais, são antigos e estão em desacordo com os biótipos dos trabalhadores, como por exemplo o caso do martelete utilizado para desobstruir válvulas, conforme evidencia o seguinte relato:

[...] tinha um tal de 'batedor' na Alunorte, tipo assim, 'um cassetete' que o guarda usa, só pra vocês terem uma ideia, 'um cassetete de ferro, o qual, a gente dava pancadas nas tubulações, pra desobstruir as mesmas'. (Luis, 58 anos. Trabalhou na Albras e na Alunorte durante 25 anos e foi aposentado por invalidez).

Portanto, fica evidente que a exposição dos trabalhadores às condições insalubres com tecnologias avançadas (Albras) e obsoletas (Alunorte), além de intenso esforço físico humano, causaram mutilações físicas nos membros superiores (mãos, braços e ombros), lesões na coluna (lombar e cervical) e membros inferiores (joelhos e pernas). Consequentemente, esses agravos à saúde provocam a diminuição da capacidade física para o trabalho e, principalmente, à vida cotidiana. Além disso, esse quadro de sofrimento, 


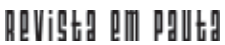

\} TRABALHADORES ACIDENTADOS/ADOECIDOS - MELO, N. S.; GOMES, V. L. B. \}

DOI: $10.12957 /$ REP.2016.27843

associado à negação de direitos sociais, torna-se um solo fértil para o desenvolvimento de transtornos mentais, melhor dizendo, "transtornos psicofísicos" (TRASPADINI; STEDILE, 2005). Desse modo, entre os sujeitos da pesquisa, a maioria $(81,81 \%-9$ trabalhadores) relatou sinais de transtornos mentais, como: ansiedade, fobias de voltar a trabalhar, depressão, síndrome do pânico e tentativas de suicídios, dentre outros.

Diante do exposto, essa situação chama a atenção para o fato de que as reivindicações dos sindicatos dos trabalhadores do Complexo do Alumínio, em geral, não têm sido voltadas para a alteração das referidas condições de trabalho, mas para fortalecê-las, devido as não raras tentativas de negociação do pagamento da insalubridade com os patrões - isto é, limitando-se a luta a essa reivindicação. Desse modo, contraria-se um dos princípios fundamentais do paradigma da saúde do trabalhador, que é a não monetarização dos riscos, ou seja, a não aceitação do acidente/adoecimento mediante o pagamento da insalubridade ${ }^{11}$ e periculosidade (MENDES; DIAS, 1991).

Tal fato é preocupante pois há, no Brasil, uma vasta legislação sobre o assunto, oferecendo orientações técnicas e científicas aos sindicatos para atuarem nas questões relacionadas à insalubridade, assim como na interdição de máquinas e equipamento de setor e de serviço que estejam colocando em risco a saúde e a vida dos trabalhadores (BRASIL, 1978; 1990; 2011).

Assim, constata-se que as negociações das entidades representativas dos mencionados trabalhadores limitam-se à exigência do pagamento da insalubridade, provavelmente vislumbrando o acesso à aposentadoria especial ${ }^{12}$. Porém, verificou-se que as empresas negam o pagamento da insalubridade e, principalmente, não investem em melhorias de condições de trabalho. O Instituto Nacional do Seguro Social (INSS), por sua vez, nega a aposentadoria especial. Tais negações, portanto, indicam que a estratégia sindical está implicando em prejuízos à saúde e à vida dos trabalhadores.

Em decorrência da concorrência intercapitalista, as empresas do Complexo do Alumínio vendem uma imagem de empresas sustentáveis no mercado internacional. Ou seja, que não acidentam e não adoecem os trabalhadores, daí a propagarem nos meios midiáticos: "[...] zerar o placar de segurança, que faz da Albrás a empresa brasileira mais segura (considerando a complexidade do negócio) de se trabalhar" (CASTILHO, 2008, p. 121). Desta maneira, a negação dos direitos sociais, especialmente os previdenciários, inicia-se no momento em que as empresas não enca-

\footnotetext{
${ }_{11}$ Conforme Brasil (1991), são atividades ou operações insalubres aquelas desenvolvidas pelo empregador que exponham os empregados a agentes nocivos à saúde, acima dos limites de tolerância fixados em razão da natureza e da intensidade do agente e do tempo de exposição aos seus efeitos.

${ }^{12}$ Com base na legislação previdenciária, aposentadoria especial é direito do segurado que tenha trabalhado durante quinze, vinte ou vinte e cinco anos, em processo de trabalho prejudicial à saúde ou à integridade física.
} 
minham o trabalhador acidentado/adoecido pelo trabalho ao INSS ${ }^{13}$, conforme abaixo:

No início eu cheguei, o próprio CEREST me indicou para que eu fosse lá no INSS para o benefício. Mas só que eu não consegui, porque o INSS me deu um documento para a empresa assinar, a assinatura da RH. Só que foi negado, a própria médica lá, negou: o RH [recursos humanos] negou, ninguém assinou o documento, nem ela me mandava para o benefício, nem ela assinava. Eu cheguei a marcar a perícia, mas não fui, porque a empresa não assinou nada, o termo de incapacidade (Marcos, 48 anos. Empregado da Alunorte, continua trabaIhando, mesmo doente).

O depoimento acima indica que o trabalhador não teve acesso ao mínimo dos direitos sociais, ou seja, ser encaminhado ao INSS para solicitar Auxílio-Doença Previdenciário/B31, na categoria de doença comum $^{14}$. Registra-se que o B31 geralmente concede ao trabalhador o afastamento do trabalho durante 90 dias, sendo que, após esse período, o mesmo deve comprovar junto ao INSS, através de documentos (CAT, exames laboratoriais, laudos médicos, dentre outros), o nexo do acidente/adoecimento com o trabalho. Entretanto, há trabalhadores acidentados/adoecidos sem condições físicas e mentais para retornarem ao trabalho e, assim, permanecem na temporalidade do B31 (MENDES et al., 2007), baseada em dias, meses e anos estipulados pelo INSS. Consequentemente, os trabalhadores temem o desligamento da política previdenciária, pois o auxílio-doença não garante o período de estabilidade no emprego. Por isso, a cada perícia médica experimentam uma tensão decorrente do temor da perda do benefício que, em geral, implica no retorno ao trabalho e uma possível demissão.

Ao acidentado/adoecido pelo trabalho, com nexo estabelecido pelo INSS, é devida uma indenização por ter sofrido lesão decorrente de acidente de qualquer natureza que tenha lhe causado sequelas definitivas (BRASIL, 1999). Dessa forma, é direito do trabalhador o acesso aos benefícios (auxílio-doença, dito acidentário, aposentadoria por invalidez, auxílio-acidente, pensão por morte) e serviços (serviço social e reabilitação profissional) peculiares a essa modalidade de agravos à saúde, sem carência, ou seja, independente do tempo de contribuição.

Por esta razão, o Auxílio Previdenciário Acidentário/B91 foi um dos direitos sociais mais almejados pelos trabalhadores do Complexo do Alumínio. Contudo, o acesso a esse direito depende da Comunicação de

\footnotetext{
${ }^{13} \mathrm{O}$ trabalhador, ao sofrer um acidente/adoecimento no trabalho, deveria ser encaminhado ao INSS a partir do $16^{\circ}$ dia, para ser avaliado pelo médico perito.

${ }^{14}$ Doenças comuns são aquelas que aparentemente não têm qualquer relação com o trabalho (MENDES; DIAS apud BRASIL, 2001).
} 
Acidente de Trabalho/CAT ${ }^{15}$, sendo que, entre os sujeitos da pesquisa, nenhum possuía a CAT preenchida pela empresa, ratificando os estudos de Salvador e Paulo Filho (2011). Sobre este assunto, constatou-se que, dentre os pesquisados, $81,81 \%$ (9), ou seja, a maioria possuía a CAT preenchida pelo Cerest-PA, enquanto que 18,18\% (2) não a tinham. Além disso, entre os acidentados/adoecidos que possuíam a CAT, 45,45\% (5), ou seja, a maioria obteve, em algum momento da sua via crucis, o benefício AuxílioDoença Acidentário/B91. Porém, as empresas questionam a veracidade da CAT nas instâncias recursais do INSS e na esfera judicial; por conta disso, na maioria das vezes, ocorre a retirada do vínculo do acidente/adoecimento com o trabalho, como veremos a seguir:

Mas é sempre muito difícil, as 'empresas em si, hoje, do grupo da Cadeia do Alumínio, elas fazem de tudo pra não reconhecer'. Pra você ter uma ideia, cada correção que nós fazemos do código 31 para o código 91, a empresa entra com recurso pra não reconhecer. Alguns que tiveram o reconhecimento já na primeira perícia pelo INSS, como doença ocupacional, a empresa também recorreu pra ser reconhecido como B31. (Representante do Sindiquímicos).

Diante do exposto, fica explícito que tanto os trabalhadores em Auxílio Previdenciário Acidentário/B91, conseguido na primeira perícia do INSS, quanto aqueles que conseguiram pela via da organização política (associação e sindicato) tiveram o Benefício/B91 alterado para o B31. Desta maneira, tal fato revela o poder das empresas para a descaracterização do nexo do acidente/adoecimento com o trabalho, logo, a invisibilidade dos impactos da exploração da força de trabalho na Amazônia paraense. Em consequência, os trabalhadores deixam de ter acesso ao Seguro de Acidente de Trabalho/SAT ${ }^{16}$ e à estabilidade no emprego de um ano após o término do Auxílio-Doença Acidentário/B91, como abaixo:

Quando eu retornei, retornei pra operação, como eu não aguentei mais, devido às crises que voltava, aí, eles me colocaram em restrição, restrita da área. Aí me colocaram em outro departamentozinho, na área mesmo, mas na parte do escritório, ajudando o assistente administrativo, dando suporte pra ele, mas continuei ganhando como operadora. Mas isso depois de muito sofrimento, mesmo! Eles só me colocaram pra lá com eles, depois de muito sofrimento, depois de muitas crises de voltar, de muitas medicações, novamente, dentro e fora da empresa. Eles ficaram com medo de eu travar definitivamente,

\footnotetext{
${ }^{15}$ Trata-se de uma ficha de notificação compulsória de acidente/doença de trabalho, devendo ser preenchida pela empresa através do médico do trabalho. Porém, nem sempre isso ocorre, pois ambos não se sentem na obrigação de fazê-la. Todavia, a CAT também pode ser preenchida pelo sindicato, família e instituições públicas. Todavia, a importância da mesma está no Laudo Especializado Médico/LEM, exclusivo do profissional médico.

${ }^{16}$ O SAT foi criado em 1967 e, de lá pra cá, já passou por inúmeras alterações, sendo a última a criação do Fator Acidentário Previdenciário (FAP). Desta forma, as alíquotas de pagamento do empregador ao SAT passaram a ser ascendentes, conforme o número de notificações de acidentes e doenças.
} 
eles me colocaram em Restrição, não foi readaptação, foi em restrição. A minha estabilidade quem tá no B91 tem pelo menos 1 ano na empresa, então, eles só me deixaram lá restrita por 1 ano e 1 mês, passou isso, eles me mandaram embora (Leila, 32 anos de idade. Trabalhou na Alunorte durante 6 anos; desses, 2 anos ficou afastada pelo benefício B31 e foi demitida).

O relato acima evidencia que a trabalhadora também teve a substituição do Auxílio-Doença Acidentário/B91 pelo B31 e, por isso, retornou ao trabalho no chão da fábrica sem ter realizado a reabilitação e/ou readaptação profissional ${ }^{17}$. Todavia, a trabalhadora, mesmo doente e sem condições de realizar as atividades profissionais, fora colocada pela empresa na condição de restrita ${ }^{18}$, que pode desencadear duas situações: a primeira, quando ocorre o agravamento das patologias apresentadas pelo trabalhador; por isso, este é novamente encaminhado ao INSS, objetivando a solicitação do auxílio-doença e, assim, permanece com auxílio B31 por longos períodos, como foi o caso de dois trabalhadores pesquisados. Na segunda, o trabalhador acidentado/adoecido continua trabalhando em outro cargo, porém, após um ano e alguns meses de estabilidade no emprego ele pode ser demitido. Portanto, a condição de restrito constitui-se em uma etapa que objetiva a expulsão do trabalhador acidentado/adoecido da empresa, pois dos três sujeitos da pesquisa demitidos, dois haviam saído dessa condição.

Pelo exposto, observou-se que existe ausência de uma política de retorno ao trabalho, tendo em vista que este também é um direito social. Sob este entendimento, Toldrá et al. (2010) afirmam que se trata de um dos aspectos mais complexos das políticas de atenção à saúde do trabalhador, pois envolve investimentos das empresas em prevenção, tratamento, reabilitação, readaptação e reinserção no trabalho. No entanto, segundo Marx (2013), o capital não tem nenhuma preocupação de oferecer condições para a recuperação da saúde dos trabalhadores, pois existe o exército industrial de reserva, do lado de fora da fábrica, controlando o valor dos salários e garantido a substituição da força de trabalho nas situações de acidente/adoecimento e/ou morte.

Ainda conforme Toldrá et al. (2010), o neoliberalismo na década de 1990 provocou o desmonte dos Centros e dos Núcleos de Reabilitação Profissional do INSS, a dispersão das equipes e a eliminação das atividades terapêuticas. Com isso, passou-se a ter um maior prolongamento dos afas-

\footnotetext{
${ }^{17}$ Conforme legislação previdenciária, a habilitação e a reabilitação profissional e social deverão proporcionar ao beneficiário incapacitado parcial ou totalmente para o trabalho, bem como às pessoas portadoras de deficiência, os meios para a (re)educação e (re)adaptação profissional e social indicados para participar do mercado de trabalho e do contexto em que vive (BRASIL, 1991).

${ }^{18}$ Condição de restrito refere-se ao retorno do trabalhador ao chão da fábrica, geralmente, no mesmo setor onde sofreu o acidente de trabalho/adoeceu, para realizar atividades "compatíveis" com o seu estado de saúde. A condição de "restrito" equipara-se à "readaptação", no entanto, aos moldes da empresa.
} 


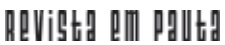

\} TRABALHADORES ACIDENTADOS/ADOECIDOS - MELO, N. S.; GOMES, V. L. B. \}

DOI: $10.12957 /$ REP.2016.27843

tamentos do trabalho devido à permanência da incapacidade. Tal fato também foi encontrado entre os sujeitos da pesquisa, pois $63,63 \%$ (7) estavam com até cinco anos de auxílio-doença, 27,27\% (3) estavam com até 10 anos, e apenas $9 \%$ (1) estavam sem tempo de benefício. Quanto à reabilitação profissional, apenas um trabalhador a realizou pelo INSS, visando à obtenção de outra profissão. No entanto, a situação se deu da seguinte maneira:

Como é que uma reabilitação entre INSS, empresa e empregado, o próprio empregado paga sua readaptação? Os 6 primeiros meses eu paguei do meu bolso e a partir do segundo semestre, a empresa começou a pagar [...]. (Luis, 58 anos. Trabalhou na Albrás e na Alunorte durante 25 anos e foi aposentado por invalidez).

Esse depoimento revelou a ocorrência de mais um direito social dos trabalhadores acidentados/adoecidos que foi negado: o direito à reabilitação profissional (direito previdenciário). Assim, ao mesmo tempo em que são negados direitos sociais, o trabalhador é expulso do emprego pelo capital. Por isso, a aposentadoria por invalidez ${ }^{19}$ apresenta-se como uma estratégia de obtenção de renda. Desse modo, o medo de desligamento da política previdenciária (dos amparados pelo B31) e a ausência de renda (dos demitidos) fizeram com que a aposentadoria por invalidez e o B91 fossem os direitos sociais mais almejados pelos sujeitos da pesquisa.

No que se refere ao direito à saúde, o serviço mais demandado pelos trabalhadores em geral (embora não se tenha acesso aos mesmos) é o diagnóstico do acidente/adoecimento, estabelecendo o nexo com o trabalho, conforme relato abaixo:

[...] Você fica abalada emocionalmente, porque dizer pra ti, que tens uma coisa que tu não tens, tu achas que não vás mais conseguir trabalhar, as pessoas te olham (não só as pessoas que vivem contigo, teus amigos, mas também as pessoas do trabalho), como se tu fosses o culpado. É esse o maior problema. E tu não és o culpado, não pedistes pra passar pro aquilo, não pedistes pra sofrer um acidente, não pedistes, não pedistes. (Rosa, 33 anos de idade. Trabalhou na Alubar por 4 anos, sofreu acidente de trabalho e foi demitida).

O relato acima é elucidativo sobre a ausência de diagnóstico de um acidente/adoecimento com o trabalho. Conforme a Política de Saúde do Trabalhador no Brasil, os Cerests são os responsáveis, no SUS, pela realização do diagnóstico do acidente/doença com o trabalho (BRASIL, 2009, 2012). Entretanto, isso nem sempre acontece, devido a certos determinantes, tais como: o poder político e econômico das empresas instaladas no referido

\footnotetext{
${ }^{19}$ Com base na legislação previdenciária, a aposentadoria por invalidez corresponde ao pagamento de proventos ao trabalhador que se encontra total ou definitivamente incapacitado para o exercício de suas atividades profissionais.
} 
Complexo de Alumínio, que, associado à histórica desigualdade regional das políticas públicas ${ }^{20}$, pode ter interferido no atraso da implantação da Política de Saúde do Trabalhador no estado do Pará21.

A propósito o município de Barcarena (PA $)^{22}$, este não dispõe de um Cerest ${ }^{23}$, estando ora sob a área de cobertura do Cerest Metropolitano/ Belém, ora do Cerest estadual (como é atualmente). Esse mosaico de determinações é agravado pela escassez de médicos no município de Barcarena, tornando-se natural um único médico exercer a medicina em três setores envolvidos com a materialidade dos direitos sociais: plano de saúde, INSS e justiça do trabalho. Essa situação foi relatada pelos sujeitos da pesquisa e ratificada nos estudos realizados por Guinalz (2007), Castro (2009) e Nogueira (2011).

No que se refere aos serviços de saúde no município de Barcarena, segundo Castro (2009), existe uma pressão política para que laudos e resultados de exames laboratoriais não apresentem subsídios analíticos para a elaboração do diagnóstico relacionando o acidente/adoecimento com o trabalho. Desse modo, a negação dos direitos dos mencionados trabaIhadores também é determinada pelo poder da ciência, especialmente a médica, que não é neutra, posicionando-se na maioria das vezes a favor dos interesses do capital. Com efeito,

[...] a não valorização do trabalhador, conduzem a uma crescente invisibilidade das doenças e acidentes relacionados ao trabalho, assim como o não reconhecimento de que o trabalho pode ser desencadeante do adoecimento. A história social do trabalho revela intrínseca relação com a saúde dos trabalhadores. Entretanto, o ocultamento dessa relação está representado pelas formas mais perversas de domínio do capital sobre o trabalho. (MENDES; WUNSCH; OLIVEIRA, 2014, p. 124).

Essa questão se agrava, ainda, devido ao fato de os trabalhadores acidentados/adoecidos, com exceção dos demitidos e dos aposentados por invalidez, serem usuários dos planos de saúde que prestam serviços às empresas do Complexo do Alumínio. Logo, estas empresas também não possuem interesse na elaboração de diagnóstico, estabelecendo o nexo entre o acidente/adoecimento com o trabalho e contribuindo, dessa forma,

\footnotetext{
${ }^{20}$ Conforme Brasil (2009), o indicador para instalação de Cerest é o número de habitantes, e não a complexidade dos processos de trabalho. Tal ordenamento da gestão nacional representa um empecilho para a consolidação da Política de Saúde do Trabalhador no estado do Pará, tendo em vista que 98\% (142) dos municípios possuem menos de 500.00 habitantes.

${ }^{21}$ A Política de Saúde do Trabalhador no estado do Pará iniciou-se na metade dos anos 1990.

22 No município de Barcarena (PA) há a ausência de representações estatais como: Cerest, agência do INSS, Ministério Público do Trabalho, dentre outras.

${ }^{23}$ A implantação de um Cerest no município de Barcarena (PA) foi pensada, em 1995, durante a realização da Mesa Redonda Internacional (MRI), em São Luís (Maranhão), que visava democratizar os recursos advindos da mitigação e/ou compensação dos danos socioambientais causados por grandes projetos implantados (SANTOS, 2009, p. 37). Contudo, tal proposta não foi materializada.
} 
com a manutenção do pacto de silêncio em torno dos acidentes/adoecimentos no trabalho. Assim:

Por que a questão do Plano de Saúde se trabalha contra. Quando você adoece, pra você ter um diagnostico relacionado ao processo de trabalho, você não consegue. Por que Plano de saúde tá do lado deles. Os médicos estão do lado deles. (Representante da ADRVDTPA).

Nessa direção, outro direito à saúde desses trabalhadores que vem sendo negado diz respeito ao não acesso à política de medicação, conforme evidenciam os relatos abaixo:

Hoje, eu tomo 6 medicamentos diariamente, eu convivo com esses remédios diariamente sem falhar: [...] 5 pra pressão porque eu sou hipertenso no nível III que é difícil de controle [...] e tomo 1 pra depressão. (Antônio, 53 anos de idade. Trabalhou na Albras e na Alunorte, sem benefício previdenciário, aguardando decisão judicial).

A parte psicológica é pelo SUS, pelo CAPS, aqui em Barcarena mesmo. Por lá, eu faço o tratamento psicológico e psiquiátrico, eles me dão uma das medicações que é o tarja preta que eu tomo e outro, eu tenho que comprar que é o da depressão (Leila, 32 anos de idade. Trabalhou na Alunorte durante 6 anos, desses, 2 anos ficou afastada pelo benefício B31 e foi demitida).

Constata-se, então, pelos relatos acima, que o acesso aos medicamentos de que esses trabalhadores fazem uso, em parte, é custeado com recursos financeiros próprios, transferindo a responsabilidade do SUS para o orçamento da família, na compra de um novo tipo de mercadoria - os remédios.

\section{Considerações finais}

Ao analisar a negação dos direitos sociais aos acidentados/adoecidos no trabalho, no Complexo do Alumínio, constatou-se que esta situação adquire um significado particular, pois Barcarena (PA) é sede de grandes projetos operacionalizados por empresas multinacionais. Cabe ressaltar que essas empresas têm como objetivo acumular capital; para tanto, fazem uso da superexploração da força de trabalho, principalmente por meio do uso de tecnologias obsoletas, que exigem grande quantidade de esforço físico para serem operadas, provocando lesões físicas na saúde dos trabalhadores, em sua maioria definitiva, e causando a interrupção forçada da força de trabalho.

O quadro de acidente/adoecimento dos trabalhadores pesquisados é agravado devido ao fato de que eles não têm acesso à maioria dos seus 


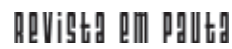

\} TRABALHADORES ACIDENTADOS/ADOECIDOS - MELO, N. S.; GOMES, V. L. B. \}

DOI: $10.12957 /$ REP.2016.27843

direitos sociais, que poderiam servir de proteção nos momentos de fragilidade física e social. Desta maneira, é possível afirmar que há tendência ao desmonte dos direitos dos trabalhadores, sob a justificativa do ajuste fiscal. Este prevê a Reforma da Previdência e a Reforma Trabalhista (primado do negociado sobre o legislado; terceirização irrestrita), com foco na desresponsabilização do Estado para com os trabalhadores brasileiros, inclusive por meio da redução dos investimentos públicos nas políticas sociais, dentre as quais aquelas voltadas à saúde do trabalhador.

A lógica perversa de acumulação capitalista existente na Amazônia paraense constitui o principal determinante para que os trabalhadores acidentados/adoecidos pelo trabalho no Complexo do Alumínio não tenham acesso ao direito social mais evidente: ser encaminhado à Previdenciária Social com um diagnóstico de adoecido pelo trabalho. Quando isso acontece, não se estabelece o nexo causal entre o acidente/adoecimento com o trabalho; contudo, o trabalhador é diagnosticado com uma doença comum. Diante disso, a aposentadoria por invalidez, acarretada por doença comum, é uma consequência dessa trajetória.

Com relação ao acesso à política de saúde, os obstáculos são maiores. Isto porque os trabalhadores acidentados/adoecidos pelo trabalho geralmente fazem uso de planos privados de saúde e só se dirigem ao SUS quando são desvinculados das empresas e/ou quando os direitos sociais encontram-se ameaçados pela falta de um diagnóstico preciso, relacionando o acidente/doença ao trabalho. Porém, a precarização dos serviços do SUS, devido à adoção das ideias neoliberais pelo governo brasileiro, é também um dos determinantes para a negação desse direito.

Já os direitos do trabalho, principalmente no retorno ao trabalho, são executados como um ritual de passagem à demissão do trabalhador acidentado/adoecido, tendo em vista que o controle do processo produtivo pertence às empresas. Este quadro de desmonte dos direitos trabalhistas e previdenciários, no Brasil, aponta a necessidade de ampliar o estudo sobre a negação dos mencionados direitos para outras áreas de implantação dos grandes projetos na Amazônia paraense, em particular, no Projeto Grande Carajás, instalado no município de Marabá. 


\section{Referências}

ABAL. Associação Brasileira do Alumínio. Disponível em: <http://www.abal. org.br/downloads/abal-rio20.pdf>. Acesso em: 21 fev. 2015.

ADRVDT/PA. Associação em Defesa dos Vitimados e Reclamantes por acidente de Trabalho da Cadeia Produtiva do Alumínio. Estudo sobre a situação dos trabalhadores acolhidos, período, 2008-2015. Barcarena-PA: 2015, mimeo.

ANTUNES. R. Os sentidos do trabalho: ensaio sobre a afirmação e a negação do trabalho. São Paulo: Boitempo, 2009.

ANUÁRIO BRASILEIRO DE PROTEÇÃO. Revista Proteção. Rio Grande do Sul: Gráfica Editora Pallotti, 2014.

BOSCHETTI, I. S. Seguridade social e trabalho: paradoxos na construção das políticas de Previdência e Assitência Social no Brasil. Brasília: UNB, 2006.

BRASIL. Decreto-Lei $n^{\circ} 5.452$ de $1^{\circ}$. de maio de 1943. Aprova a Consolidação das Leis doTrabalho. 1943. Disponível em: <http://www.planalto. gov.br/ccivil_03/de-creto-lei/Del5452.htm>. Acesso em: 13 ago. 2015.

- Ministério do Trabalho e Emprego - Secretaria de Inspeção do Trabalho/SIT. Portaria n $n^{o} 3.21408$ de 06 de 1978. Aprova e Regulamenta as Normas Regulamentadoras de Segurança e Saúde do Trabalho. 1978. Disponível em: <http://www.guiatrabalhista.com.br/legislacao/nr/nr3.htm>. Acesso em: 24 nov. 2015.

. Constituição Federal de 1988. 1988. Disponível em: <http://www. planalto.gov.br/ccivil_03/constituicao/constituicao.htm>. Acesso em: 25 mai. 2014.

. Lei 8.080 de 19 de setembro de 1990. Dispõe sobre as condições para a promoção, proteção e recuperação da saúde, a organização e o funcionamento dos serviços correspondentes e dá outras providências. 1990. Disponível em: <http://www.planalto.gov.br/ccivil_03/leis/l8080.htm>. Acesso em: 24 mai. 2014.

Lei no 8.213, de 24 de julho de 1991. Dispõe sobre os planos de benefícios da Previdência Social e dá outras providências. 1991. Disponível em: <http://www.planalto.gov.br/ccivil_03/leis/l8213cons.htm>. Acesso em: 24 mai. 2014.

. Decreto que Regulamenta a Previdência Social. 1999. Disponível em: <http://www.planalto.gov.br/ccivil o3/decreto/d3048.htm>. Acesso em: 13 ago. 2015. 


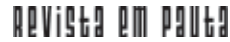

\} TRABALHADORES ACIDENTADOS/ADOECIDOS - MELO, N. S.; GOMES, V. L. B. \}

DOI: $10.12957 /$ REP.2016.27843

BRASIL. Ministério da Saúde. Doenças relacionadas ao trabalho: manual de procedimentos para os serviços de saúde. Brasília: Ministério da Saúde, 2001. Disponível em: <http://dtr2001.saude.gov.br/editora/produtos/livros/ pdf/02_0388_M1.pdf>. Acesso em: 24 mai. 2014.

. Ministério da Saúde. Portaria $n^{o}$ 2.728, de 11 de novembro de 2009. Dispõe sobre a Rede Nacional de Atenção Integral à Saúde do Trabalhador (Renast). 2009. Disponível em: <http://portal.saude.gov.br/ portal/arquivos/pdf/portaria_renast_2728.pdf>. Acesso em: 24 mai. 2014.

- Ministério do Trabalho e Emprego/Secretaria de Inspeção do Trabalho/SIT. Portaria $n^{o .} 199$ de 17 de janeiro de 2011. Altera a Norma Regulamentadora de Segurança e Saúde no Trabalho/Embargo ou Interdição-NR-3. 2011. Disponível em: <http://www.normaslegais.com.br/ legislacao/portariasit199_2011.htm> Acesso em: 24 nov. 2015.

. Ministério da Saúde. Portaria no 1.823, de 23 de agosto de 2012. Institui a Política Nacional de Saúde do Trabalhador e da Trabalhadora. 2012. Disponível em: <http://bvsms.saude.gov.br/bvs/saudelegis/gm/2012/ prt1823_23_08_2012.html> Acesso em: 24 mai. 2014.

. Ministério da Saúde. PB - Parecer Consubstanciado CEP - 1233 601, de 17 de setembro de 2015. Disponível em http://aplicacao.saude. gov.br/plataformabrasil/visao/administrador/4×4Novo/detalharProjeto AgrupadorApreciacao.jsf. Acesso em 17 set. 2015.

CASTILHO, D. R. O Programa Vida Saudável e suas repercussões na vida dos trabalhadores da ALBRÁS - Alumínio Brasileiro S/A. Dissertação (Mestrado - Programa de Pós-Graduação em Ciências Sociais), Universidade Federal do Pará, Belém (PA), 2008 (mimeo).

CASTRO, H. A. A saúde dos trabalhadores da cadeia produtiva do alumínio. In: ALMEIDA, R. (Org.). Alumínio na Amazônia: saúde do trabalhador, meio ambiente e movimentos sociais. São Luís: Fórum Carajás, 2009.

COUTINHO, C. N. Contra a corrente: ensaios sobre a democracia e socialismo. São Paulo: Cortez, 2008.

COUTO, B. R. O direito social e a assistência social na sociedade brasileira: uma equação possível? São Paulo: Cortez, 2010.

FALEIROS, V. P. O trabalho da política: saúde e segurança dos trabalhadores. São Paulo: Cortez, 2010.

FERREIRA, W. As metamorfoses da questão social: uma crônica do salariado - uma resenha. 2008. Disponível em: <htpp//:www.webartigos.com/artigos/ as-metamorfoses-da-questao-social-uma-cronica-do-salario-de-robertcastel-uma-resenha/109586/>. Acesso em: 30 nov. 2016.

GOMES, R. et al. Organização, processamento, análise e interpretação de dados: o desafio da triangulação. In: MINAYO, M. C. S.; ASSIS, S. G.; 


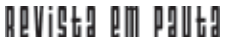

\} TRABALHADORES ACIDENTADOS/ADOECIDOS - MELO, N. S.; GOMES, V. L. B. \}

DOI: $10.12957 /$ REP.2016.27843

SOUZA, E. R. (Org.). Avaliação por triangulação de métodos. Abordagem de Programas Sociais. Rio de Janeiro: Fiocruz, 2005.

GOMES, V. L. B.; CASTRO, E. R. Trabalhadores da Albras e sua organização política. Novos Cadernos NAEA, Belém: Naea, v. 7, n. 1, jun. 2004.

GUINALZ, J. P. Trabalho, alienação e adoecimento na Cadeia de Produção de Alumínio em Barcarena. 2007. Dissertação (Mestrado - Programa de Pós-Graduação em Desenvolvimento Sustentável do Trópico Úmido/ PDTU), Universidade Federal do Pará, Belém (PA), 2007 (mimeo).

HOBSBAWM, E. J. Mundo do trabalho: novos estudos sobre a história operária. São Paulo: Paz e Terra, 2000.

LACAZ, F. A. C.; GOMEZ, C. M. Saúde do trabalhador: novas-velhas questões. In: BRASIL. Ministério da Saúde. $3^{a}$ Conferência Nacional de Saúde do Trabalhador: 3a CNST: "trabalhar, sim! adoecer não!": coletânea de textos. Brasília: Ministério da Saúde, 2005.

LAURELL, A. C; NORIEGA, M. O processo de produção e saúde: trabalho e desgaste operário. São Paulo: Hucitec, 1989.

LEAL, A. L. Amazônia: o aspecto político da questão mineral. Dissertação (Mestrado - Programa Internacional de Mestrado em Planejamento do Desenvolvimento/Plades), Universidade Federal do Pará, Belém (PA), 1988 (mimeo).

LOURENÇO, E. A. Agravos à saúde dos trabalhadores no Brasil: alguns nós críticos. Pegada, São Paulo, ano 11, n. 1, 2011. Disponível em: htpp://< www.revista.fct.unesp.br/index.php/pegada/article/viewfile/927/940>. Acesso em: 15 set. 2014.

MARQUES, G. da S.; TRINDADE, R. B.; Para além da SPVEA: elementos para uma interpretação da intervenção estatal na Amazônia. In: TRINDADE, R. B. (Org.). Seis décadas de integração estatal na Amazônia: a SPVEA, auge e crise do ciclo ideológico do desenvolvimento brasileiro. Belém: PakaTatu, 2014.

MARSHALL, T. H. Cidadania, classe social e status. Rio de Janeiro: Zahar, 1967.

MARTINELLI, M. L. O uso de abordagens qualitativas na pesquisa em Serviço Social. Pesquisa qualitativa: um instigante desafio. São Paulo: Veras, 1999. MARX, K. O capital. Livro 1. Crítica da economia política. São Paulo: Beltrand, 1994.

- O capital. Crítica da economia política. Livro 2. Rio de Janeiro: Civilização Brasileira, 2013. 


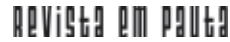

\} TRABALHADORES ACIDENTADOS/ADOECIDOS - MELO, N. S.; GOMES, V. L. B. \}

DOI: $10.12957 /$ REP.2016.27843

MENDES, J. M. R.; WUNSCH, D. S.; OLIVEIRA, P. A. B. Política de Saúde do Trabalhador: desafios históricos e contemporâneos. In: GARCIA, M. L. T (Org.). Análise da Política de Saúde brasileira. Vitória: Edufes, 2014. Disponível em: <http://repositorio.ufes.br/bitstream/10/1030/1/Livro\%20 edufes $\% 20$ Analise $\% 20$ da $\% 20$ Politica $\% 20 \mathrm{de} \% 20$ Saude $\% 20$ Brasileira.pdf>. Acesso em: 20 mai. 2015.

MENDES, J. M. R.; et al. A dimensão social do acidente de trabalho na família: uma perspectiva de investigação no campo da proteção social. In: SIMPÓSIO BRASILEIRO DE SAÚDE DO TRABALHADOR (SIMBRAST). Rio de Janeiro, 2007. Disponível em: <http://hdl.handle.net/10183/11728>. Acesso em: 20 nov. 2014.

MENDES, R; DIAS, E. Da medicina do trabalho à saúde do trabalhador. Saúde Pública, São Paulo, v. 25, n. 5, 25 mai. O 1991. Disponível em: < http://www.scielo.br/pdf/rsp/v25n5/03.pdf>. Acesso em: 24 mai. 2014.

MONTEIRO, M. A; MONTEIRO, E. F. Amazônia: os (des)caminhos da Cadeia Produtiva do Alumínio. In: ALMEIDA, R. (Org.). Alumínio na Amazônia: saúde do trabalhador, meio ambiente e movimentos sociais. São Luís: Fórum Carajás, 2009.

MOREIRA, C. A. L.; MAGALHÃES, E. S. de. Um novo padrão exportador de especialização produtiva? Considerações sobre o caso brasileiro. Revista da Sociedade Brasileira de Economia Política, Niterói, n. 38, jan. 2014. Disponível em: http://<Revista.sep.org.br/index.php/sep/article/view/56/93>. Acesso em: 30 nov. 2016.

NASCIMENTO, M. A. C. O paradoxal desenvolvimento do estado do Pará: efeitos no social. In: SCHERER, E. (Org.). Questão social na Amazônia. Manaus: Edua, 2009.

NOGUEIRA, L. S. M. O sofrimento negado: trabalho, saúde/doença, prazer e sofrimento dos trabalhadores do alumínio do Pará-Brasil. 2011. Tese (Doutorado - Programa de Planejamento do Desenvolvimento), Universidade Federal do Pará, Belém (PA), 2011 (mimeo).

PARÁ. Secretaria de Saúde Púbica. Centro de Referência Estadual em Saúde do Trabalhador. Quadro Demonstrativo de Acolhimento do período de 2008 a 2014. Belém, 2014 (mimeo).

PEREIRA, P. A. P. Discussões conceituais sobre política social como política pública e direito de cidadania. In: BOSCHETTI, I. et al (Org.). Política social no capitalismo: tendêncas contemporâneas. São Paulo: Cortez, 2008.

PNUD. Atlas do Desenvolvimento Humano no Brasil. Bacarena, PA. 2013. Disponível: <http://www.atlasbrasil.org.br/2013/pt/perfil_m/barcarena_pa>. Acesso em: 30 ago. 2014. 


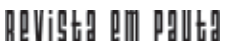

\} TRABALHADORES ACIDENTADOS/ADOECIDOS - MELO, N. S.; GOMES, V. L. B. \}

DOI: $10.12957 /$ REP.2016.27843

RIVERO, S.; COONEY, P. A Amazônia como fronteira da acumulação do capital. In: DINIZ, M. B. (Org.). Desafios e potencialidades para a Amazônia do século XXI. Belém: Paka-tatu, 2011.

SALVADOR, L.; PAULO FILHO, O. Higidez física e mental: a efetividade das leis da infortunística como instrumento de dignificação do trabalhador: mens sana in corpore sano. In: VIZZACCARO-AMARAL, A. L.; MOTA, D. P.; ALVES, G. (Org.). Trabalho e saúde: a precarização do trabalho e a saúde do trabalhador no século XXI. São Paulo: LTR, 2011.

SANTIAGO, J. C. S. Trabalho e capital na Amazônia Oriental: movimento operário versus reestruturação produtiva no Complexo Albras-Alunorte: 1990-2005. 2007. Dissertação (Mestrado - Programa de Ciências Sociais), Universidade Federal do Pará, Belém (PA), 2007.

SANTOS, M. P. Os caminhos do alumínio. In: ALMEIDA, R. (Org.). Alumínio na Amazônia: saúde do trabalhador, meio ambiente e movimentos sociais. São Luís: Fórum Carajás, 2009.

SANTOS, W. G. Décadas de espanto e uma apologia democrática. Rio de Janeiro: Rocco, 1998.

SOARES, L. T. O desastre social. Rio de Janeiro: Record, 2003.

TOLDRÁ, R. C. et al. Facilitadores e barreias para o retorno ao trabalho: a experiência de trabalhadores atendidos em um Centro de Referência em Saúde do Trabalhador (SP). Revista Brasileira de Saúde Ocupacional, São Paulo, v. 35, n. 121, mar. 2010. Disponível: <http://www.scielo.br/pdf/ rbso/v35n121/03.pdf $>$. Acesso: 12 mar. 2015.

TRASPADINI, R.; STEDILE, J. P. (Org.). Ruy Mauro Marini: vida e obra. São Paulo: Expressão Popular, 2005.

VILELA, R. A. G. et al. Desafios da vigilância e da prevenção de acidentes do trabalho. São Paulo: LTR, 2003.

Recebido em 28 de março de 2016.

Aprovado para publicação em 25 de agosto de 2016.

DOI: 10.12957/rep.2016.27843

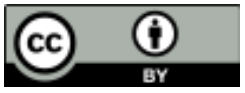

A Revista Em Pauta: Teoria Social e Realidade Contemporânea está licenciada com uma Licença Creative Commons Atribuição 4.0 Internacional. 